\title{
A technical study to economise the amount of zinc used in the production of radiogallium
}

\author{
Shaban A. Kandil', Mogahed Al-Abyad*1, Zoltan Szücs ${ }^{2}$ \\ ${ }^{1}$ Physics Department - Cyclotron Facility, Nuclear Research Centre, Atomic Energy Authority, Cairo, Postal \\ Code 13759, Egypt \\ ${ }^{2}$ Institute of Nuclear Research, Hungarian Academy of Sciences (ATOMKI), Debrecen, Hungary
}

\begin{abstract}
For the production of radiogallium, the targets were prepared in two forms, namely, electroplated metal and pressed oxide. The target holder was selected from $\mathrm{Cu}$-metal as a circular disk. The experimental yields of ${ }^{66,67,68} \mathrm{Ga}$ produced from both irradiated ${ }^{\text {nat }} \mathrm{ZnO}$ and zinc metal targets are given and compared with the estimated yields as well as with the previously reported values. The $\mathrm{ZnO}$ target developed in this work appears to be more convenient and economical for local production of short-lived radiogallium, e. g. ${ }^{66} \mathrm{Ga}$ and ${ }^{68} \mathrm{Ga}$.
\end{abstract}

Keywords: Radiogallium, nat $\mathrm{Zn}$ and nat $\mathrm{ZnO}$-targets, electrodeposition, pressing technique, radiogallium production yield

\footnotetext{
*Author for correspondence. Tel: +2 0244691 743; Fax: +2 0246220086

E-mail address:alabyad_m@yahoo.com
} 


\section{Introduction}

Radiogallium $\left({ }^{66} \mathrm{Ga},{ }^{67} \mathrm{Ga}\right.$ and $\left.{ }^{68} \mathrm{Ga}\right)$ are widely used in nuclear medicine, commonly as a trivalent citrate compound for imaging, also as valuable agents in the detection and localization of certain neoplasms and inflammatory lesion [1-3]. The decay data of those gallium radioisotopes are given in Table 1 [4]. They are produced by irradiations of enriched $\mathrm{Zn}$ isotopes by proton at various cyclotrons. Furthermore, bombardment of natural $\mathrm{Zn}$ with protons of sufficient energies also resulted in the formation of those radionuclides [5-8].

The cyclotron target is generally prepared by electrodeposition of zinc on different metal backings, namely, gold, copper and steel [9-13]. In preliminary work we demonstrated the electroplating of acid-dissolved $\mathrm{Zn}$ in aqueous solutions. However, the quality was unacceptable due to the complex compounds formed between the bath residuals and the plated metal. Adjustments in the plating current density, plating bath temperature, and solvent washes of plated $\mathrm{Zn}$ did not remedy the poor quality and degradation of material, resulting in bead formation. To complicate matters, the formation of free radicals from the plating solution created a hydrogenation reaction at the cathode which caused it to become embrittled. In other cases, a small amount of an adequate surfactant in the electrodeposition bath results in beneficial quality change of the deposits, namely the homogeneity $[14,15]$.

In the present work we concentrated on the simple Zn-targetry and thereby saving the amount of zinc used. The experimental yields of ${ }^{66,67,68} \mathrm{Ga}$ in irradiated targets were investigated.

\section{Experimental}

\subsection{Targetary}

\subsubsection{Chemicals and reagents}

High purity Zn-metal (99.97\%, Koch-light laboratories Ltd., England); potassium bicarbonate, hydrochloric acid, obtained from Sisco research laboratories PVT-LTD Mumbai, India.

\subsubsection{Preparation of Zn-targets via electrodeposition}

Zinc targets used for this purpose were prepared by electrodeposition using a cell that correlates with an electrodeposition cell given in the literature $[9,16]$. Firstly, pure metallic zinc (1-2 g) was transformed to zinc sulfate. The electrodeposition of $\mathrm{Zn}$ on target holder was carried 
out at constant current intensity and continual stirring of the electrolyte. The aqueous solution of zinc sulfate $(\mathrm{pH} 3.5-4.5)$ was made in distilled water $(50 \mathrm{~mL})$. A copper cathode and a platinum anode were used. The electrolytic cell takes $50 \mathrm{~mL}$ of solution. The cell voltage was adjusted to 6 $\mathrm{V}$ and the current density to $35 \mathrm{~mA} / \mathrm{cm}^{2}$ [9]. The applied current decreased during the electrodeposition process due to the decrease in the conductivity of the solution as the zinc layer grew. Also the $\mathrm{pH}$ of the solution decreased; therefore, it is necessary to neutralize it by adding drops of concentrated solution of ammonia. A layer of 200-300 mg of zinc was obtained.

\subsubsection{Preparation of $\mathrm{ZnO}$ - target via pressing technique}

Pure metallic zinc $(0.3 \mathrm{~g})$ was transformed to zinc sulfate that was consequently transformed to zinc carbonate. To avoid the releasing of gas during an irradiation process, zinc carbonate was heated to a temperature above $400{ }^{\circ} \mathrm{C}$, whereby it was converted to $\mathrm{ZnO}$. The loss in the weight corresponds to the carbon dioxide released.

\subsection{Design of the target holder for pressing technique}

The substrate selected was $\mathrm{Cu}$-metal due to its good thermal conductivity. It is designed as a circular disk fitted in the irradiation chamber in the cyclotron radioisotope beam line. The thickness of the $\mathrm{Cu}$-disk is $3 \mathrm{~mm}$ with a central circular groove of $5 \mathrm{~mm}$ radius, and $2.7 \mathrm{~mm}$ depth (Fig. 1), in which the $\mathrm{ZnO}$ powder was pressed under a stress of $1 \mathrm{ton} / \mathrm{cm}^{2}$ and then covered by a Havar foil of $10 \mu \mathrm{m}$ thickness. The covering foil was fixed by a metal ring to avoid contamination during the irradiation resulting from distraction of the pressed powder. The ring had a small cut in its circumference to facilitate the handling.

The irradiated surface area is an important parameter which helps in the enhancement of thermal conductivity for the $\mathrm{ZnO}$-target. The irradiated area and area density in the present work for the $\mathrm{ZnO}$-target were $0.785 \mathrm{~cm}^{2}$ and $382 \mathrm{mg} / \mathrm{cm}^{2}$, respectively. By increasing the target area and consequently decreasing the area density, it is possible to get a thin $\mathrm{ZnO}$-target. The thin target is the boundary between the cover foil and the target holder. If the target is thin this would lead to a good heat removal.

\subsection{Irradiation and yield measurements}

Both the nat $\mathrm{Zn}$ metal and nat $\mathrm{ZnO}$ targets were subjected to increasing beam current tests. The irradiations were performed at the MGC-20E cyclotron in Debrecen, Hungary, at beam current 
of $1,5,10,12$ and $15 \mu \mathrm{A}$ of the incident proton energy $16 \mathrm{MeV}$ for one hour. The targets were cooled by water jet from the back and by circulating helium at the front.

\subsubsection{Target inspection}

The electroplated ${ }^{\text {nat }} \mathrm{Zn}$ metal target remained unaffected by irradiations up to $15 \mu \mathrm{A}$. The ${ }^{n a t} \mathrm{ZnO}$ target as shown in Fig. 1 was irradiated by beam currents starting from $1 \mu \mathrm{A}$ upwards. A visual inspection showed that the target remains stable without cracks or spot burn even when the current was raised to $5 \mu \mathrm{A}$. At $10 \mu \mathrm{A}$ small cracks start to appear. At 12 and $15 \mu \mathrm{A}$ irradiation, it changed to pale yellow but still maintained its stable state. At currents over $15 \mu \mathrm{A}$ the target was damaged but it still remained in its groove.

The targets could not be measured directly due to high activity of the $\mathrm{Cu}$ activation products. The target material zinc was therefore dissolved in $7 \mathrm{M} \mathrm{HCl}$. A 1-10\% fraction of the dissolved irradiated target was then taken and the activity measured with standard high resolution $\gamma$-ray spectrometer consisting of a HPGe detector coupled to a multi-channel analyzer. The peak area analysis was done using the software Gamma-vision (Version 5.1, EG \& G ORTEC). The fractions were measured at different and large distances to avoid coincidence losses. Detector efficiencies for different measuring distances $(0,510,20$ and $50 \mathrm{~cm})$ were carefully determined using different standard sources of ${ }^{133} \mathrm{Ba},{ }^{60} \mathrm{Co},{ }^{137} \mathrm{Cs},{ }^{22} \mathrm{Na}$ and ${ }^{154,152} \mathrm{Eu}$.

\section{Results and discussion}

The present work was mainly directed towards preparation of ZnO-target by the pressing technique and studying the circumstances, such as preparation of the powder target, holder design, irradiation and handling of the target holder after irradiation. Also investigation of experimental yields of ${ }^{66,67,68} \mathrm{Ga}$ in both irradiated $\mathrm{Zn}$ metal target and $\mathrm{ZnO}$-target was the aim.

Experimental work showed that about $300 \mathrm{mg}$ of $\mathrm{Zn}$ metal was needed in the preparation of the $\mathrm{ZnO}$-target, which is much lower than the amount of $1500 \mathrm{mg}$, used in the $\mathrm{Zn}$-target preparation.

\subsection{Radiogallium yields}

The present experimental yields of ${ }^{66,67,68} \mathrm{Ga}$ produced in pressed zinc oxide irradiated with $16 \mathrm{MeV}$ protons of beam currents of $1,5,10,12$ and $15 \mu \mathrm{A}$ are shown in Fig. 2. The activity increases linearly as the beam current increases. The values for ${ }^{68} \mathrm{Ga}$ at 12 and $15 \mu \mathrm{A}$ are, however, 
too high, possibly due to large counting errors in strong samples because of the very weak gamma ray intensity $(3 \%)$.

Table 2 gives the irradiation conditions and the experimental yields of ${ }^{66,67,68} \mathrm{Ga}$ at EOB for both targets ( $\mathrm{Zn}$-target and $\mathrm{ZnO}$-target) as well as the calculated yields given recently by Aslam et al [8], after normalization to natural abundance of zinc. As expected from reports by Szelecsényi et al. [17], and Aslam et al. [8], in this work the measured yields are lower than the calculated ones. However, the experimental yield loss of ${ }^{67} \mathrm{Ga}$ is too high as compared to that of ${ }^{66,68} \mathrm{Ga}$ with respect to the calculated yield. It is known that ${ }^{67} \mathrm{Ga}$ comes from $16 \mathrm{MeV}$ proton activation of ${ }^{67,68} \mathrm{Zn}$, with their abundances of 4.1 and $18.7 \%$, respectively. Hence, ${ }^{68} \mathrm{Zn}$ contributes strongly to its formation via the ${ }^{68} \mathrm{Zn}(\mathrm{p}, 2 \mathrm{n}){ }^{67} \mathrm{Ga}$ reaction, whose threshold is, however, rather high. Thus a small uncertainty in the proton energy could lead to extreme loss in its activity.

Moreover the $\mathrm{ZnO}$-target showed ${ }^{66,67,68} \mathrm{Ga}$ yields 16 to $20 \%$ lower than those from the $\mathrm{Zn}$-target. This is due to the loss of some proton energy by absorption in the oxygen content and due to the presence of lesser number of $\mathrm{Zn}$ atoms in $\mathrm{ZnO}$ than in metallic $\mathrm{Zn}$. There is an agreement between the present yields from the ${ }^{\text {nat }} \mathrm{Zn}$-target and the reported yields (Table 3) $[1,18,19]$.

The activities of ${ }^{66,67} \mathrm{Ga}$ in the $\mathrm{ZnO}$-target could be raised by an irradiation for $20 \mathrm{~h}$ of 15 $\mu \mathrm{A}$ beam current to about $30 \mathrm{GBq}$ of ${ }^{66} \mathrm{Ga}$ and about $700 \mathrm{MBq}$ of ${ }^{67} \mathrm{Ga}$. The ${ }^{68} \mathrm{Ga}$ yield reaches saturation (about $25 \mathrm{GBq}$ ) after an irradiation of $2 \mathrm{~h}$. Thus sufficient quantities of radiogallium could be produced using the above described target.

\section{Conclusion}

The two targets, i. e. $\mathrm{Zn}$-metal and $\mathrm{ZnO}$, are prepared by consuming 1.5 and $0.3 \mathrm{~g}$ of $\mathrm{Zn}$ metal, respectively. This is due to the low electroplating yield in the case of the metal target. In industrial scale production of ${ }^{67} \mathrm{Ga}$ it is not a problem because the electrolytic bath residue is reprocessed. Furthermore, the target is subjected to irradiation at several hundred $\mu \mathrm{A}$ which leads to large amounts of ${ }^{67} \mathrm{Ga}$ and makes the process economical. At a laboratory scale, however, for the quick production of ${ }^{66} \mathrm{Ga}$ or ${ }^{68} \mathrm{Ga}$, the simple targetry of $\mathrm{ZnO}$-target leads to quantities of ${ }^{66,68} \mathrm{Ga}$ sufficient for practical applications. The experimental yields of radiogallium in the case of $\mathrm{ZnO}$ target are 16 to $20 \%$ smaller than those from the Zn-target. Nonetheless, the preparation of the $\mathrm{ZnO}$-target is much easier and more economical. Thus the $\mathrm{ZnO}$-target developed in this work could 
be conveniently used for local production of short-lived radiogallium (e. g. ${ }^{66} \mathrm{Ga}$ and ${ }^{68} \mathrm{Ga}$ ) but it is not a complete alternative to the $\mathrm{Zn}$-metal target used for large scale production of ${ }^{67} \mathrm{Ga}$.

\section{References}

1. Lewis, M. R., Reichert, D. E., Laforest, R., Margenau, W. H., Shefer, R. E., Klinkowstein, R. E., Hughey, B. J., Welch, M. J.: Production and purification of gallium-66 for preparation of tumor-targeting radiopharmaceuticals. Nucl. Med. and Biol. 29, 701 (2002).

2. Collery, P., Keppler, B., Madoulet, C., Desoize, B.: Gallium in cancer treatment. Critical Reviews in Oncology/Hematology 42, 283 (2002).

3. Khan, M.U., Khan, S., El-Refaie, S., Win, Z., Rubello, D., Al-Nahhas, A.: Clinical indications for Gallium-68 positron emission tomography imaging. Eur. J. Surg. Oncol. 35, 561 (2009).

4. Firestone, R. B., Ekström, L. P., Chu, S. Y.F.: Isotope Explorer. LBNL, Lund University, Version 2.23, (2003).

https://www-nds.iaea.org/pgaa/isoexpl/isoexpl.htm

5. Hermanne, A., Szelecsényi, F., Sonck, M., Takács, S., Tárkányi, F., Van den Winkel, P.: New cross section data on ${ }^{68} \mathrm{Zn}(\mathrm{p}, 2 \mathrm{n}){ }^{67} \mathrm{Ga}$ and ${ }^{\text {nat }} \mathrm{Zn}(\mathrm{p}, \mathrm{xn}){ }^{67} \mathrm{Ga}$ nuclear reactions for the development of a reference data base. J. Radioanal. Nucl. Chem. 240, 623 (1999).

6. Szelecsényi, F., Steyn, G.F., Kovács, Z., van derWalt, T.N., Suzuki, K., Okada, K., Mukai, K.: New cross-section data for the nat $\mathrm{Zn}(\mathrm{p}, \mathrm{x}){ }^{66} \mathrm{Ga},{ }^{68} \mathrm{Zn}(\mathrm{p}, 2 \mathrm{n}){ }^{67} \mathrm{Ga}$ and ${ }^{\text {nat }} \mathrm{Zn}(\mathrm{p}, \mathrm{x}){ }^{67} \mathrm{Ga}$ nuclear reactions up to $100 \mathrm{MeV}$. Nucl. Instrum. Methods Phys. Res. B 234, 375 (2005).

7. Szelecsényi, F., Kovács, Z., Nagatsu, K., Fukumura, K., Suzuki, K., Mukai, K.: Investigation of direct production of ${ }^{68} \mathrm{Ga}$ with low energy multiparticle accelerator. Radiochim. Acta 100, 5 (2012).

8. Aslam, M. N., Amjed, N., Qaim, S.M.: Evaluation of excitation functions of the ${ }^{68,67,66} \mathrm{Zn}(\mathrm{p}, \mathrm{xn}){ }^{68,67,66} \mathrm{Ga}$ and ${ }^{67} \mathrm{Zn}(\mathrm{p}, \alpha){ }^{64} \mathrm{Cu}$ reactions: Validation of evaluated data through comparison with experimental excitation functions of the ${ }^{n a t} \mathrm{Zn}(\mathrm{p}, \mathrm{x}){ }^{66,67} \mathrm{Ga}$ and ${ }^{\text {nat }} \mathrm{Zn}(\mathrm{p}, \mathrm{x})^{64} \mathrm{Cu}$ processes. Applied Radiation and Isotopes 96, 102 (2015).

9. Neirinckx, R. D.: A high-yield production method for gallium-67 using an electropolated natural zinc or enriched Zn-66 target. Int. J. Applied Radiation and Isotopes 27, 1 (1976).

10. Kastleiner, S., Coenen, H. H., Qaim, S. M.: Possibility of production of ${ }^{67} \mathrm{Cu}$ at a small-sized cyclotron via the $(p, \alpha)$-reaction on enriched ${ }^{70} \mathrm{Zn}$. Radiochim. Acta 84, 107 (1999). 
11. Stoll, T., Kastleiner, S., Shubin, Yu. N., Coenen, H. H., Qaim, S. M.: Excitation functions of proton induced reactions on ${ }^{68} \mathrm{Zn}$ from threshold up to $71 \mathrm{MeV}$, with specific reference to the production of ${ }^{67} \mathrm{Cu}$. Radiochim. Acta 90, 309 (2002).

12. Hilgers, K., Stoll, T., Skakun, Y., Coenen, H. H., Qaim, S. M.: Cross-section measurements of the nuclear reactions ${ }^{\text {nat }} \mathrm{Zn}(\mathrm{d}, \mathrm{x}){ }^{64} \mathrm{Cu},{ }^{66} \mathrm{Zn}(\mathrm{d}, \alpha){ }^{64} \mathrm{Cu}$ and ${ }^{68} \mathrm{Zn}(\mathrm{p}, \alpha \mathrm{n}){ }^{64} \mathrm{Cu}$ for production of ${ }^{64} \mathrm{Cu}$ and technical development for small-scale production of ${ }^{67} \mathrm{Cu}$ via the ${ }^{70} \mathrm{Zn}(\mathrm{p}, \alpha){ }^{67} \mathrm{Cu}$ process. Appl. Radiat. Isotopes 59, 343 (2003).

13. Gomes, A., da Silva Pereira, M.I.: Pulsed electrodeposition of $\mathrm{Zn}$ in the presence of surfactants. Electrochimica Acta 51, 1342 (2006).

14. Tripathy, B. C., Das, S. C., Hefter, G. T., Singh, P.: Zinc electrowinning from acidic sulfate solutions: Part I: Effects of sodium lauryl sulfate. J. Appl. Electrochem. 27, 673 (1997).

15. Trejo, G., Ruiz, H., Ortega Borges, R., Meas, Y.: Influence of polyethoxylated additives on zinc electrodeposition from acidic solutions. J. Appl. Electrochem. 31, 685 (2001).

16. Paradellis, T., Vourvopoulos, G., Paleodimopoulos, E.: The production of gallium-67 with a Tandem accelerator. J. Radioanal. Nucl. Chem. 84, 263 (1984).

17. Szelecsényi, F., Boothe, T.E., Takács, S., Tárkányi, F., Tavano, E.: Evaluated cross section and thick target yield data bases of $\mathrm{Zn}+\mathrm{p}$ processes for practical applications. Appl. Radiat. Isot. 49, 1005 (1998).

18. Dahl, J. R., Tilbury, R. S.: The use of a compact multi-particle cyclotron for the production of ${ }^{52} \mathrm{Fe},{ }^{67} \mathrm{Ga},{ }^{111} \mathrm{In}$ and ${ }^{123} \mathrm{I}$ for medical purposes. Int. J. Appl. Radiat. Isotopes 23, 431 (1972).

19. Al-Saleh, F. S., Mugren, K. S., Azzam, A.: Excitation function measurements and integral yields estimation for ${ }^{n a t} \mathrm{Zn}(\mathrm{p}, \mathrm{x})$ reactions at low energies. Appl. Radiat. Isot. 65, 1101(2007).

\section{Figures Caption}

Fig. 1. $\mathrm{Cu}$-holder containing the $\mathrm{ZnO}$-target, Havar foil cover and steel ring. 
Fig. 2.Radiogallium yields, produced in the ${ }^{\text {nat }} \mathrm{ZnO}$-target irradiated at $16 \mathrm{MeV}$ proton energy for one hour, against the beam current (a) ${ }^{66} \mathrm{Ga}$, (b) ${ }^{67} \mathrm{Ga}$ and (c) ${ }^{68} \mathrm{Ga}$. 